\section{Association between schizophrenia and social inequality at birth: case-control study}

\author{
GLYNN HARRISON, DAVID GUNNELL, CRIS GLAZEBROOK, KIM PAGE \\ and ROSEMARY KWIECINSKI
}

People with schizophrenia are more likely to occupy lower socio-economic positions and reside in areas characterised by higher social deprivation at the time of first diagnosis (Croudace et al, 2000; Eaton \& Harrison, 2001). It is unclear whether these factors contribute to aetiology or whether they result from social segregation caused by prodromal symptoms. Goldberg \& Morrison (1963) examined fathers' social class by occupation in male patients with schizophrenia and appeared to demonstrate that downward social segregation occurred after birth. Evidence is accumulating, however, for an association between risk of schizophrenia and urbanisation of birthplace (Lewis et al, 1992; Mortensen et al, 2000), and obstetric complications, themselves associated with an increased risk of schizophrenia, are also generally socially patterned. We have investigated the relationship between social inequality at birth and the later development of schizophrenia in a first-episode sample. We examined two indicators of socio-economic position recorded at the time of birth and available from routine sources: father's social class; and the social characteristics of the area of residence of the mother.

\section{METHOD}

\section{Sample}

The design of the first-episode psychosis study on which this analysis is based is described in detail elsewhere (Brewin et al, 1997). Briefly, every first episode case of psychosis $(n=168)$ presenting to specialist mental health services over a 2 -year period was identified from a defined catchment area covering a population of 600000 people in Nottingham. Cases were identified using a psychosis screen and subject to in-depth assessments. 'First-episode' was defined as a first contact with mental health services for a psychotic illness; there was no 'cut off' point for duration of untreated illness, and any cases with prior episodes of undetected illness also were included. Diagnostic categories were assigned using ICD-10 (World Health Organization, 1993) following psychopathological assessments with the Schedules for Clinical Assessment in Neuropsychiatry (SCAN; World Health Organization, 1994). Family history was recorded using the Family History Research Diagnostic Criteria (Andreasen et al, 1977) based upon multiple sources of information including case notes, patients and, where possible, informants. Cases were allocated to ethnic group on the basis of place of birth of parents: for the purposes of the present analysis, cases were identified as African-Caribbean if one or both parents had been born in the Caribbean (Harrison et al, 1997).

\section{Study design}

A matched case-control design was used. Of 168 incident cases arising over the 24month study recruitment period, 94 had been born in the study catchment area and these form the basis of this analysis. The birth certificate of each of these cases was located from local birth registers and four age-gender-matched controls were obtained by selecting the next four births registered at the same registry office. Cases and controls thus were matched for date of birth (to within 6 weeks) and area of birth registration. Because our cases were incident episodes of psychotic disorder in people who had been born in Nottingham, to ensure comparability of the source populations for cases and controls we eliminated, before analysis, those controls $(43 \%$ of the total) who were no longer resident in Nottingham (according to the Family Health Services Authority register) at the time of case ascertainment.

We extracted father's occupation and mother's address from the birth certificates for cases and controls. Father's occupation was assigned to a social class on the basis of the Registrar General's Classification of Occupations (Office of Population Censuses and Surveys, 1991). We used the mother's address to assign each individual to an area measure of socio-economic deprivation, the Nottinghamshire County Council 'index of need'. This was based mainly upon 1971 census data (Nottinghamshire County Council, 1975), corresponding to the median birth year of the study sample. The county was divided into zones, composed of combinations of enumeration 
districts, designed to cover areas of broadly similar social character. Each of the zones was scored on 20 indicators representing income, unemployment, crime, housing and other dimensions of deprivation. The scores then were aggregated to give a single (unweighted) summary measure of 'deprivation', allowing them to be ranked and stratified into four broad categories. Because of the relatively small numbers in the present study, we decided a priori to create a two-level indicator of deprivation by collapsing these four groups into two broad categories of 'above average' or 'below average' social need.

\section{Analysis}

We analysed associations of the two indicators with all psychotic disorders. Then we assessed separately the associations for nonaffective, non-substance-related psychosis ('broadly defined schizophrenia', ICD-10 F20-29) and non-schizophrenic psychosis (ICD-10 F30-33 and F1x). Conditional logistic regression analyses were carried out using the Stata software package (StataCorp, 1999). Tests for linear trend across social class categories were based on the continuous measure for social class. Because no information on the ethnicity or family history of controls was available, the potential confounding effects of these factors were assessed by repeating the main analyses but excluding African-Caribbean cases as well as cases with a family history of schizophrenia.

A three-level childhood deprivation score, combining information on place of birth and parental occupation, then was produced as follows: 0 , if the father was social class I-III and the mother lived in a non-deprived area; 1 , if the father was social class IV/V or the mother lived in a deprived area; 2 , if the father was social class IV/V and the mother lived in a deprived area.

Appropriate interaction terms were fitted to the models to investigate whether associations between childhood socioeconomic deprivation and schizophrenia differed by gender or age (categorised into two groups - above or below the median age of 25 years for the sample).

\section{RESULTS}

The 168 cases identified in the original sample yielded an age-standardised annual incidence rate of 28.7/100 000 population. Of the 94 cases born in Nottingham, information on father's occupation on the birth certificates enabled classification into social class I-V groupings in 88 cases. Data on at least one matched control subject were available for 82 of these cases and these, together with their 198 matched controls, constitute the subjects included in the models presented below. The median age of the cases was 25.5 years (range 16-64) and $61 \%$ were males. There was no difference between African-Caribbeans and other cases in the proportion of SCAN ratings that were based upon full respondent interviews (Harrison et al, 1997). Fifty-eight (71\%) were classified into broadly defined schizophrenia (ICD-10, F20-29). Twenty-four $(29 \%)$ had a non-schizophrenic psychotic illness (ICD-10 F30-33 and F1x). Table 1 shows the distribution of father's social class and mother's residence by deprivation 'need' index for the cases of adult-onset psychosis and controls.

Table 2 shows the odds ratios $(95 \% \mathrm{CI})$ for the association of adult-onset psychosis with paternal social class and area-level deprivation. For all psychoses there were significant associations with the two indicators examined independently: social class and area of residence at birth. When associations with broad schizophrenia and other psychoses were examined separately there was some evidence that associations are stronger in relation to area of residence for broad schizophrenia. The small number of cases limited the power of analyses examining relationships with other psychotic disorders.

The combined childhood deprivation score showed a highly significant linear association with all psychoses and for broad schizophrenia, although the association was weaker for non-schizophrenic psychoses.
Table I Distribution of paternal social class and deprivation score of area of residence at birth of incident cases of psychosis with matched controls

\begin{tabular}{lccr}
\hline $\begin{array}{l}\text { Social class } \\
\text { of father }\end{array}$ & Controls & $\begin{array}{c}\text { 'All } \\
\text { psychosis' } \\
\text { cases }\end{array}$ \\
\hline I & 4 & 3 & 7 \\
II & 17 & 6 & 23 \\
III non-manual & 16 & 5 & 21 \\
III manual & 116 & 25 & 141 \\
IV & 28 & 28 & 56 \\
V & 17 & 15 & 32 \\
Total & 198 & 82 & 280
\end{tabular}

Area 'need' index'

$\begin{array}{lrrr}0 & 89 & 27 & 116 \\ I & 109 & 55 & 164 \\ \text { Total } & 198 & 82 & 280\end{array}$

I. Area 'need' index: 0, below average need; I, above average need.
Table 2 Odds ratios $(95 \% \mathrm{Cl})$ for association between socio-economic position at birth and adult-onset psychosis (based on the 82 cases and their respective controls where classification of paternal social class into I-V groupings was possible)

\begin{tabular}{|c|c|c|c|}
\hline \multicolumn{4}{|l|}{ Paternal social class } \\
\hline I/II (reference category) & 1.0 & 1.0 & 1.0 \\
\hline $\mathrm{III}(\mathrm{nm} / \mathrm{m})$ & $0.6(0.2-1.6)$ & $0.4(0.1-1.2)$ & $1.5(0.3-7.6)$ \\
\hline $\mathrm{IV} / \mathrm{V}$ & $2.6(1.0-6.9)$ & $1.8(0.6-5.8)$ & $4.7(0.8-29.3)$ \\
\hline$P$ value for linear trend & $P=0.010$ & $P=0.023$ & $P=0.21$ \\
\hline Residence in deprived compared & $1.9(1.0-3.7)$ & $2.7(1.2-6.5)$ & I.I (0.4-3.2) \\
\hline with non-deprived area & $P=0.046$ & $P=0.021$ & $P=0.86$ \\
\hline \multicolumn{4}{|l|}{ Combined deprivation score } \\
\hline 0 & 1.0 & 1.0 & 1.0 \\
\hline I & $1.9(0.9-4.0)$ & $2.1(0.8-5.5)$ & $1.5(0.4-5.4)$ \\
\hline 2 & $6.3(2.7-15.2)$ & $8.1(2.7-23.9)$ & $3.6(0.8-16.9)$ \\
\hline$P$ value for linear trend & $P<0.001$ & $P<0.001$ & $P=0.11$ \\
\hline
\end{tabular}

$\mathrm{nm}$, non-manual; $\mathrm{m}$, manual. 
For the latter group, confidence intervals were wide and, as stated above, the analysis lacked statistical power. There was no significant interaction between gender and the combined deprivation score with respect to overall risk of psychosis $(P=0.81)$. There were weak interactions between age and the summary deprivation score with respect to all psychosis $(P=0.16)$ and the broad schizophrenia grouping $(P=0.18)$. In a stratified analysis the odds ratio for broad schizophrenia per unit increase in deprivation score was 4.6 (95\% CI=1.9$10.9)$ for subjects aged $>25$ years and 2.1 (95\% $\mathrm{CI}=1.0-4.2)$ for subjects aged $<25$ years.

\section{Family history of psychosis and African-Caribbean family background}

The association between indicators of deprivation at birth and adult-onset psychosis could be explained by family history of psychotic illness. Parental illness would have led to reduced occupation status and geographical segregation in deprived urban areas. There is also an increased risk of psychosis in those with a family background of migration to the UK from the Caribbean (Harrison et al, 1997), and African-Caribbean families might be more likely to reside in areas of higher deprivation. To assess these possible confounding effects, analyses were repeated for cases without a family history of psychosis in a first-degree relative (Table 3 ) and cases with neither a family history of psychosis nor African-Caribbean ethnicity (Table 4). Because both of these analyses are based on smaller numbers of cases, they have lower statistical power than those based on the complete data-set. Restriction of the analysis to these subgroups without a positive family history did not alter greatly the strength of the observed associations reported in Table 2, although the magnitude of the odds ratios was attenuated after exclusion of the African-Caribbean cases and their matched controls, suggesting some confounding of the main effects. An analysis excluding only AfricanCaribbean cases showed a similar degree of attenuation.

\section{DISCUSSION}

Our data show that socio-economic deprivation at birth is associated with increased risk of developing schizophrenia and related non-affective psychoses in later life. There was a strong association in cases with broadly defined schizophrenia, but for other (mostly affective) psychoses the case numbers were small and the power of analysis was low. The association with broadly defined schizophrenia persisted but was attenuated slightly after restricting the analysis to those cases who were not of African-Caribbean family origin.

Table 3 Odds ratios $(95 \% \mathrm{Cl})$ for association between socio-economic position at birth and adult-onset psychosis, excluding those cases with a family history of schizophrenia and related psychoses

\begin{tabular}{|c|c|c|c|}
\hline & $\begin{array}{l}\text { All psychoses } \\
\text { ( } n=71 \text { cases) }\end{array}$ & $\begin{array}{l}\text { Broad schizophrenia } \\
\qquad(n=50)\end{array}$ & $\begin{array}{l}\text { Other (non-schizophrenic) } \\
\text { psychotic illness } \\
(n=2 \mathrm{I})\end{array}$ \\
\hline \multicolumn{4}{|l|}{ Paternal social class } \\
\hline I/II (reference category) & 1.0 & 1.0 & 1.0 \\
\hline III $(\mathrm{nm} / \mathrm{m})$ & $0.7(0.3-1.9)$ & $0.5(0.1-1.7)$ & $1.4(0.3-7.4)$ \\
\hline $\mathrm{IV} / \mathrm{V}$ & $2.6(0.9-7.3)$ & $2.0(0.6-6.9)$ & $3.9(0.6-25.0)$ \\
\hline$P$ value for linear trend & $P=0.027$ & $P=0.045$ & $P=0.33$ \\
\hline Residence in deprived compared & $2.0(1.0-4.0)$ & $2.9(1.2-7.2)$ & I.I (0.4-3.5) \\
\hline with non-deprived area & $P=0.047$ & $P=0.023$ & $P=0.85$ \\
\hline \multicolumn{4}{|l|}{ Combined deprivation score } \\
\hline 0 & 1.0 & 1.0 & 1.0 \\
\hline $\mathrm{I}$ & $1.6(0.7-3.5)$ & $2.2(0.8-6.3)$ & $0.7(0.2-3.2)$ \\
\hline 2 & $5.7(2.3-14.3)$ & $7.7(2.4-24.4)$ & $3.3(0.6-17.3)$ \\
\hline$P$ value for linear trend & $P<0.001$ & $P<0.001$ & $P=0.17$ \\
\hline
\end{tabular}

nm, non-manual; m, manual.

Table 4 Odds ratios $(95 \% \mathrm{Cl})$ for association between socio-economic position at birth and adult-onset psychosis, excluding those with a family history of psychosis and those of African-Caribbean ethnicity

$\begin{array}{lcc}\text { All psychoses } & \text { Broad schizophrenia } & \text { Other (non-schizophrenic) } \\ (n=51 \text { cases }) & (n=42) & \text { psychotic illness } \\ & & (n=19)\end{array}$

\begin{tabular}{llll}
\hline Paternal social class & & & \\
I/II (reference category) & $I .0$ & $I .00$ & $I .0$ \\
III $(\mathrm{nm} / \mathrm{m})$ & $0.7(0.3-2.0)$ & $0.5(0.2-1.8)$ & $I .2(0.2-6.7)$ \\
IV/V & $2.6(0.9-7.3)$ & $I .7(0.5-6.0)$ & $5.9(0.8-42.8)$ \\
P value for linear trend & $P=0.07$ & $P=0.19$ & $P=0.2 \mathrm{I}$ \\
Residence in deprived compared & $I .7(0.8-3.4)$ & $2.3(0.9-6.0)$ & $0.9(0.3-3.1)$ \\
$\quad$ with non-deprived area & $P=0.16$ & $P=0.08$ & $P=0.92$ \\
Combined deprivation score & & & \\
0 & $I .0$ & $I .0$ & $I .0$ \\
I & $I .3(0.5-3.0)$ & $2.0(0.7-5.7)$ & $0.4(0.1-2.6)$ \\
2 & $4.7(I .8-12.2)$ & $5 . I(I .6-16.9)$ & $4.3(0.7-30.0)$ \\
$P$ value for linear trend & $P=0.002$ & $P=0.007$ & $P=0.13$ \\
\hline
\end{tabular}

nm, non-manual; m, manual. 
diagnosis were used throughout. The record of family history of psychotic disorder was the weakest aspect of the methodology: we did not carry out a systematic interview with all first-degree relatives, but relied upon interviews with patients, case notes and, where available, an interview with an informant. It is possible that this resulted in some underreporting.

Several other methodological limitations require consideration. Although the study design was a population-based case-control study, case finding was based upon contact with secondary services rather than a systematic community survey. The observed association with social deprivation may have been for risk of making contact with secondary mental health services when developing psychotic symptoms, rather than for risk of psychotic illness per se. Although we cannot eliminate this possibility altogether, we think that this is unlikely in view of evidence from community surveys that most cases make contact with specialist services at some point in the course of the disorder (Link \& Dohrenwend, 1980).

The selection of controls required consideration. First, no attempt was made to determine whether controls had schizophrenia. However, because the population prevalence of schizophrenia is low (Office of Population Censuses and Surveys, 1995), the effects of any possible misclassification of controls would be small. Furthermore, such misclassifications would tend to reduce the size of any effect and bias our findings towards the null hypothesis. Second, Nottingham has three birth registry offices and, because both cases and controls would be more likely to register locally, we probably overmatched for geographical area. This also would tend to bias our findings towards the null hypothesis of no difference in area of residence. Finally, confounding could be explored only in a limited way because we were unable to obtain information on the ethnicity and family history of the controls.

A further issue in the interpretation of these data is the potential effect of possibly different migration patterns among cases and potential controls. Although we excluded controls that had migrated out of Nottingham, it is possible that socio-economic factors may influence the migration patterns of people during the prodromal period of psychotic illness: the outward migration from Nottingham of preschizophrenia cases could have been greater among more affluent cases, producing a biased distribution of social class and area of residence among the remaining cases. We believe that this is an unlikely explanation, but the issue remains incapable of being resolved conclusively within the design and sample sizes available in our study.

We based our deprivation score upon available data close to the median birth date of our sample and we do not have data for the longer term stability of this scoring distribution, covering the age range of our sample. There is evidence from other studies, however, that an area's socio-economic characteristics remain relatively stable over long time periods (Dorling et al, 2000). Finally, it should be recognised that the exclusion of cases that were not born in Nottingham resulted in a sizeable reduction in the number of cases eligible for inclusion in our sample. Our findings therefore only apply to people with schizophrenia who continue to reside in a local area after birth: the association cannot be generalised to all schizophrenic disorders.

\section{Previous studies}

Although Goldberg \& Morrison (1963) and Hare et al (1972) found that social class distribution by paternal background was comparable to that of the general population, our findings are similar to those of Turner \& Wagenfield (1967) and Castle et al (1993), who reported associations with lower paternal social class. Recent British (Done et al, 1994; Jones et al, 1994) and Finnish (Makikyro et al, 1997) studies, which take advantage of well-defined birth cohorts followed through part of the risk period for schizophrenia, report an association with high paternal socio-economic status. However, in the study by Jones et al (1994) the number of cases was small $(n=30)$ and in both Done's (1994) and Makikyro's (1997) studies the subjects were followed for only part of the risk period (to age 28 and age 23 years, respectively) for developing schizophrenia. These analyses thus were confined to early-onset cases. It is possible that any association between parental social class and schizophrenia is stronger for later-onset cases, which would be consistent with our finding of borderline interactions between age and the summary deprivation score with respect to all psychosis. Larger, carefully defined samples are required to clarify these complex issues and, although we developed a combined measure to illustrate accumulated risk (after reporting separate analyses for our two indicators), future studies should continue to examine these (and other) markers separately.

\section{Social inequalities and the aetiology of schizophrenia}

Measures of socio-economic position are, at best, proxy markers for factors linked more directly to the risk of schizophrenia. There are a number of causal possibilities, including biological risk factors such as exposure to infections and other toxic agents, and non-biological factors such as social and psychological stressors linked to the degree of social fragmentation and individual social capital (Hare, 1956; Van Os et al, 2000). It is becoming increasingly difficult to distinguish between causes that have a clear material basis and those that might be located in the 'environment' or in mental activity. In addition, although our data suggest that there are independent associations with individual-level and arealevel characteristics, cumulative effects are likely to accrue over the life course and it is probable that causal relationships in schizophrenia are mediated by complex gene-environment interactions. Whatever the nature of the risk factors involved, our data suggest that environmental factors play a significant role in the aetiology of schizophrenia.

\section{REFERENCES}

Andreasen, N. C., Endicott, J., Spitzer, R. L., et al (1977) The family history method using diagnostic criteria. Archives of General Psychiatry, 34, 1229-1235.

Brewin, J., Cantwell, R., Dalkin, T., et al (1997) The incidence of schizophrenia in Nottingham. A comparison of two cohorts, 1978-80 and 1992-94. British Journal of Psychiatry, I7I, 140-144.

Castle, D. J., Scott, K., Wessely, S., et al (1993) Does social deprivation during gestation and early life predispose to later schizophrenia? Social Psychiatry and Psychiatric Epidemiology, 28, I-4.

Croudace, T., Bloom, R., Jones, P., et al (2000) Non linear relationship between a measure of social deprivation, psychiatric admission prevalence and the incidence of psychosis. Psychological Medicine, 30, 177-185.

Done, D. J., Crowe, T. J., Johnstone, E. C., et al (1994) Childhood antecedents of schizophrenia and affective illness: social adjustment at ages 7 and II. BMJ, 309, 699-703.

Dorling, D., Mitchell, R., Shaw, M., et al (2000) The Ghost of Christmas Past: health effects of poverty in London in 1896 and 1991. BMJ, 32I, 1547-I55I.

Eaton, W. \& Harrison, G. (200I) Life chances, life planning and schizophrenia: a review and interpretation 
of research on social deprivation. International journal of Mental Health, 30, 58-8I.

\section{Goldberg, E. M. \& Morrison, S. L. (1963) \\ Schizophrenia and social class. British Journa} of Psychiatry, 109, 785-802.

Hare, E. H. (1956) Family setting and the urban distribution of schizophrenia. Journal of Mental Science, 102, 753-760.

_ , Price, J. S. \& Slater, E. (1972) Parental social class in psychiatric patients. British Journal of Psychiatry, I2I, 515-534.

Harrison, G., Glazebrook, C., Brewin, J., et al (1997) Increased incidence of psychotic disorders in African Caribbean migrants to the UK. Psychological Medicine, 17, 799-806.

Jones, P., Rodgers, B., Murray, R., et al (1994) Child development risk factors for adult schizophrenia in the British 1946 birth cohort. Lancet, 344, 1398-1402.

Lewis, G., David, A. \& Andreasson, S. A. P. (1992) Schizophrenia and city life. Lancet, 340, 137-140.

Link, G. \& Dohrenwend, B. P. (1980) Formulation of hypotheses about the ratio of untreated to treated cases in the true prevalence studies of functional psychiatric disorders in adults in the United States. In Mental IIIness in the United States: Epidemiologic Estimates (eds B. P. Dohrenwend, B. S. Dohrenwend, M. S. Gould, et al), pp. 133-148. New York: Praeger.

\section{Makikyro, T., Isohanni, M., Moring, J., et al (1997)} Is a child's risk of early onset schizophrenia increased in the highest social class. Schizophrenia Research, 23 (3), 245-252.

Mortensen, P. B., Pedersen, C. B., Westergaard, T., et al (2000) Effects of family history and place and season of birth on the risk of schizophrenia. New England Journal of Medicine, 340 (8), 603-608.

Nottinghamshire County Council (1975) County Deprived Area Study. Nottingham: Nottinghamshire County Council.

Office of Population Censuses and Surveys (1991) Standard Occupation Classification. London: HMSO.

_ (1995) The Prevalence of Psychiatric Morbidity among Adults Living in Private Households. London: HMSO.

StataCorp (1999) Stats Statistical Software (release 6.0) College Station, TX: Stata Corporation.

Turner, R. J. \& Wagenfield, M. O. (1967) Occupationa mobility and schizophrenia: an assessment of the social

\section{CLINICAL IMPLICATIONS}

Indicators of social inequality at birth and in early life are associated with increased risk of schizophrenia in later life.

- The known association between schizophrenia and social deprivation at the time of diagnosis is not attributable entirely to inter-generation social selection and intrageneration social 'drift'.

- These data add to accumulating evidence for the role of environmental factors in the aetiology of schizophrenia.

\section{LIMITATIONS}

Cases were identified from patients making first-ever contact with secondary services, rather than by comprehensive (household) community survey.

- The method for measuring family history probably resulted in some underreporting.

- During the period between birth and case identification there may have been different patterns of migration in the source and control populations.

G. HARRISON, FRCPsych, Division of Psychiatry, University of Bristol; D. GUNNELL, PhD, Department of Social Medicine, University of Bristol; CRIS GLAZEBROOK, PhD, K. PAGE, MRCPsych, R. KWIECINSKI, BSc, Department of Psychiatry, University of Nottingham

Correspondence: Glynn Harrison, Division of Psychiatry, 4I St Michael's Hill, University of Bristol BS8 3JT, UK

(First received 20 November 2000, final revision 20 April 200I, accepted 26 April 200I)

causation and social selection hypothesis. American Sociological Review, 32, 104-113.

Van Os, J., Driessen, G., Gunther, N., et al (2000) Neighbourhood variation incidence of schizophrenia. Evidence for person-environment interaction. British Journal of Psychiatry, 176, 243-248.
World Health Organization (1993) Tenth Revision of the International Classification of Diseases and Related Health Problems (ICD-10). Diagnostic Criteria for Research. Geneva: WHO.

- (1994) Schedules for Clinical Assessment in Neuropsychiatry II. Geneva: WHO. 